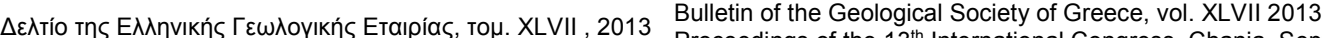

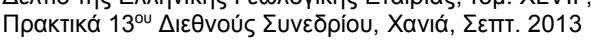

\title{
THE UPGRADING AMENABILITY OF THE PHOSPHATE DEPOSITS OF WESTERN GREECE
}

\author{
Pantelaki O. ${ }^{1}$, Bellis G. ${ }^{1}$ and Stamboliadis E. ${ }^{{ }^{*}}$ \\ ${ }^{I}$ Technical University of Crete, ${ }^{*}$ Corresponding author elistach@mred.tuc.gr
}

\begin{abstract}
In Epirus, Western Greece, there exist extensive low quality phosphate rock deposits. Although phosphate fertilizers are extensively used in agriculture and Greece imports about 200.000 ton/y, of phosphate ore in addition to ready to use phosphate fertilizers, these deposits are not yet exploited.

This work examines the possibility to upgrade this type of ore using different methods of mineral processing. The results obtained are poor and unsatisfactory for commercial exploitation. The main reasons are the type of $\mathrm{P}_{2} \mathrm{O}_{5}$ bearing mineral and mainly it's intergrowth with the associated gangue ones.

The present work examines the mineralogy and chemistry of the ore, the energy size relationship in crushing using a centrifugal crusher, its behavior in grinding, its behavior to heavy liquid treatment and its floatability using oleic acid as well as dialkyl-orthophosphate collectors. The later were specially prepared for this purpose. Finally the ore was calcined at $950{ }^{\circ} \mathrm{C}$ in order to dissociate the existing calcite to $\mathrm{CaO}$, which is subsequently selectively hydrolyzed to give $\mathrm{Ca}(\mathrm{OH})_{2}$ that is finely disseminated in the pulp and can be separated from the coarser phosphate grain.
\end{abstract}

Key words: Energy size relationship, Flotation, calcination and hydrolysis.

\section{Пері́ $\eta \psi \eta$}

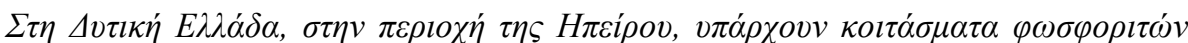

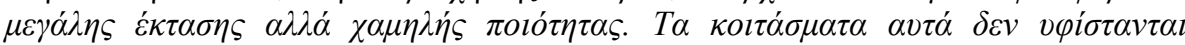

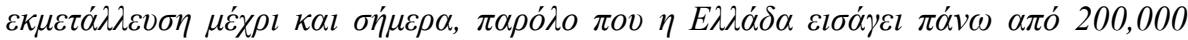

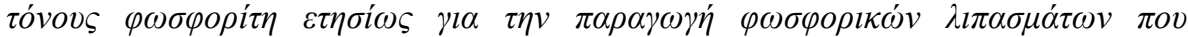

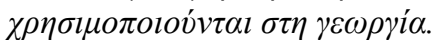

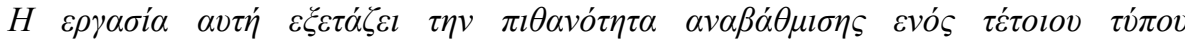

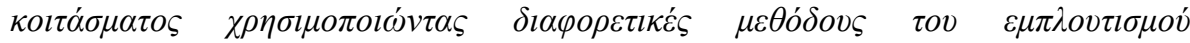

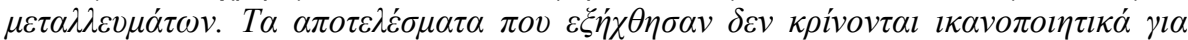

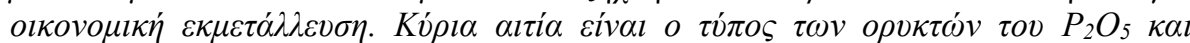

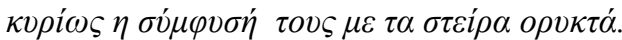

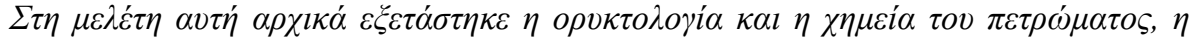

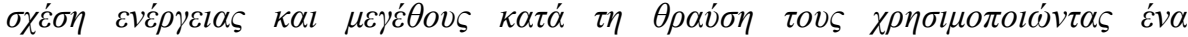

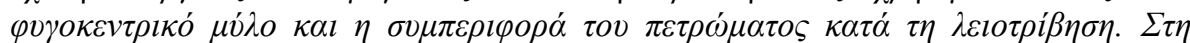

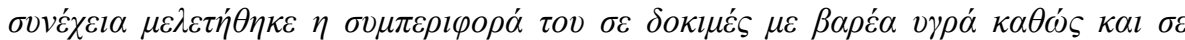

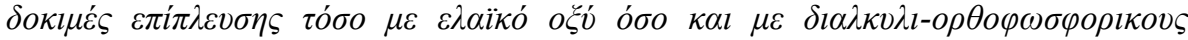

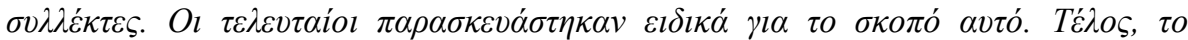

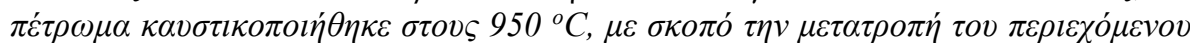

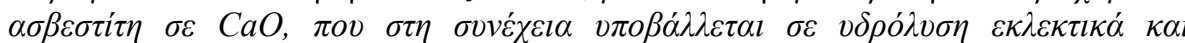

XLVII, No $3-2000$ 


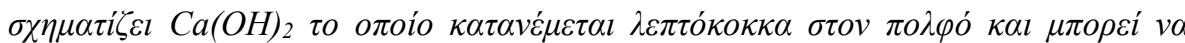

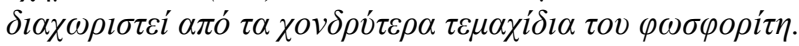

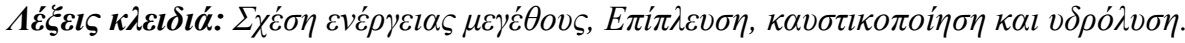

\title{
1. Introduction
}

The need for the development of the Greek mineral resources is very urgent, especially in times of economic recession and negative foreign commercial balance. The imports of phosphate ores, to cover the needs of the fertilizers plant in Kavala are of the order of 200.000 ton/year not including the imports of ready to use phosphate fertilizers products.

In Epirus, Western Greece, there are millions of tons of low grade phosphate ore deposits that remain unexploitable, mainly due to their low grade. The $\mathrm{P}_{2} \mathrm{O}_{5} \%$ content varies between $10-30 \%$ with an average of $20 \%$ (Tsailas et al., 1980). The present work is an effort; to investigate the properties of the above material and at the same time reveal the reasons of the existing difficulty to obtain a commercial grade concentrate. The ore sample under investigation was collected by IGME, the Institution of Geological and Metallurgical Research in Preveza and forwarded to the Technical University of Crete.

The present work examines the chemical composition of the ore sample, its mineralogical composition and its macroscopic as well as the microscopic structure together with the intergrowth of the mineral phases present. Since the scope of the work is not only mineralogical but is mainly oriented to the production of a commercial concentrate from the raw material, several mineral processing procedures were also tried. These methods were chosen according to the mineralogical and structural characteristics of the ore. Macroscopically it appears that the ore consists of parallel zones, a few millimeters thick that vary in their $\mathrm{P}_{2} \mathrm{O}_{5}$ content. Microscopically the minerals appear to be very finely intergrown and the liberation is not easy.

Initially the ore was tested in a centrifugal crusher to study its breakage energy requirements and to obtain the energy size relationship. Heavy liquids laboratory tests were curried out designed mainly for relative coarse grains above $1 \mathrm{~mm}$ in order to take advantage of the macroscopic zone structure of the ore. As the liberation of the minerals present in all zones is very bad the ore sample was ground further down in an effort to liberate the minerals. Grinding tests were performed to decide the products size to be used for mineral separation at a lower particle size than the one used for heavy liquids. The process most likely to succeed at a low particle size after grinding is froth flotation. Two types of anionic collectors were used namely the oleic acid and dialkyl-phosphate sodium salts of varying alkyl chain length.

The physical separation processes used did not provide a commercial grade concentrate and for this reason it was decided to proceed with a thermal decomposition process followed by hydrolysis one. Although the cost of such a process is very high for commercial application it was selected in order to investigate such a possibility for theoretical purposes only.

\section{Description of the Various Experimental Procedures}

Primary crushing of the initial $-50 \mathrm{~mm}$ sample was performed in a laboratory scale jaw crusher to a $-30 \mathrm{~mm}$ particle size. A centrifugal crusher was used for secondary crushing to finer sizes as well as a means to investigate the breakage energy for different size classes of the material and to establish the energy size relationship. This crusher is equipped with a rotating disc capable to run at preset frequencies and thus control the kinetic energy of the material before crushing. For the grinding of the material down to flotation size a laboratory rod mill $(\mathrm{D}=20 \mathrm{~cm} \mathrm{~L}=28 \mathrm{~cm})$ was used, running at $85 \%$ of its critical rotation frequency and equipped with $9 \mathrm{~kg}$ of steel rods.

XLVII, No $3-2001$ 
The sizing of the material was achieved in a laboratory screen, using $20 \mathrm{~cm}$ diameter screens with sieve openings at a constant ratio of two. The shaking of the screen was mechanically performed on a vibrating shaker. For the fine size fractions the laser beam size analysis was also used.

The chemical analysis of the samples was performed using a XR Fluorescence analysis apparatus. The loss on ignition (LOI) tests were performed in the available electric furnace at $950{ }^{\circ} \mathrm{C}$.

The minerals identification was achieved using an XR Difractometer followed by the investigation of thin and polished sections with a metallurgical microscope.

The heavy liquids used for separation were mixtures of tetrabromoethane (sg 2.96) and carbon tetrachloride (sg 1.6) in suitable analogies (proportions) to obtain the required densities.

For the flotation tests a 4 liter laboratory cell was used with controlled rotation frequency of its rotor.

\section{Description of the Material}

Macroscopic examination of the particles of the initial sample, about $50-70 \mathrm{~mm}$ in size, shows that all rock particles present have two parallel sides that follow the direction of zones with alternating dark and light coloring of pale brown. A thin section of the sample presented in Figure 1, was prepared vertical to the direction of the colored zones. A careful inspection can distinguish a vertical light color zone surrounded by darker ones. The only mineral crystals that can be identified are bright crystals of calcite, while the rest is microcrystalline

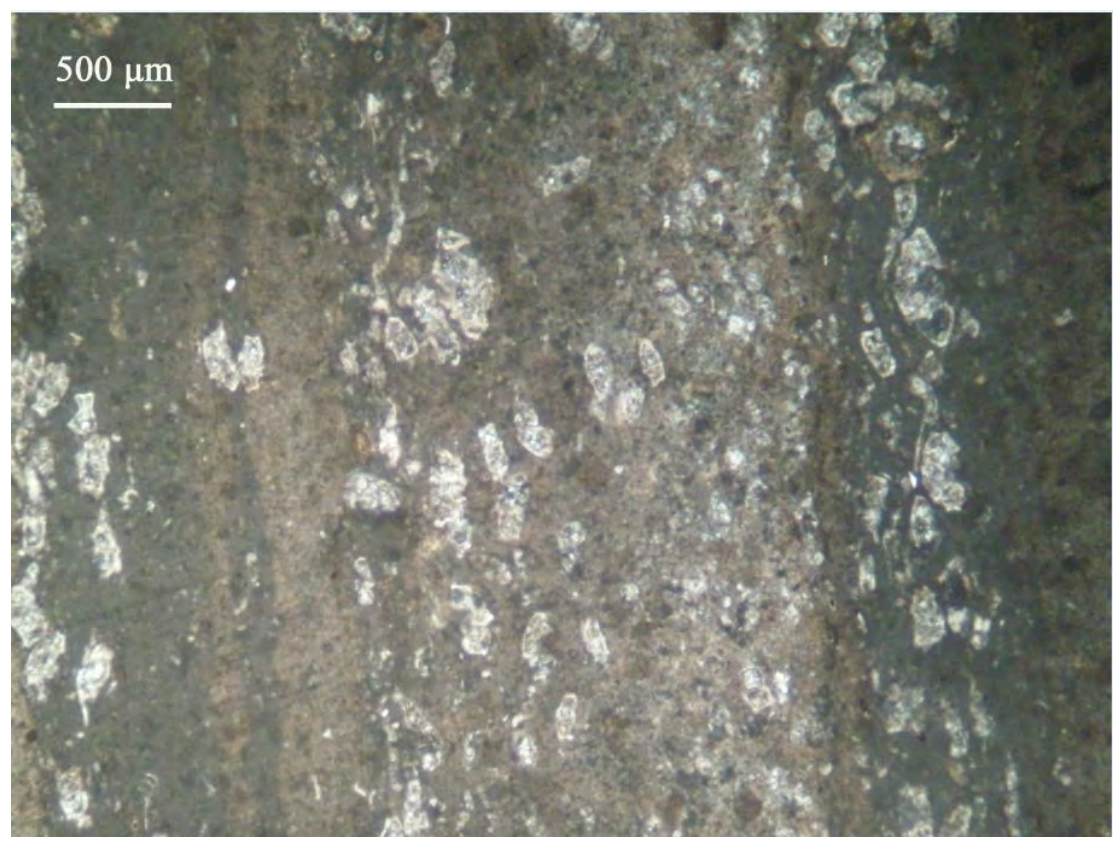

Figure 1 - Thin section, transmitted light //Nicols.

The initial sample after crushing to $-4 \mathrm{~mm}$ was tested for its physical and chemical properties. Some grains of the material were used to prepare a polished section that appears in Figure 2. It is obvious that no crystals can be identified and all grains look the same

The mineralogical composition obtained by XRD appears in Table 1, which shows that the most abundant mineral is calcite followed by francolite, a carbonate rich fluoroapatite (Perdikatsis,1991). Quartz is a minority mineral. 


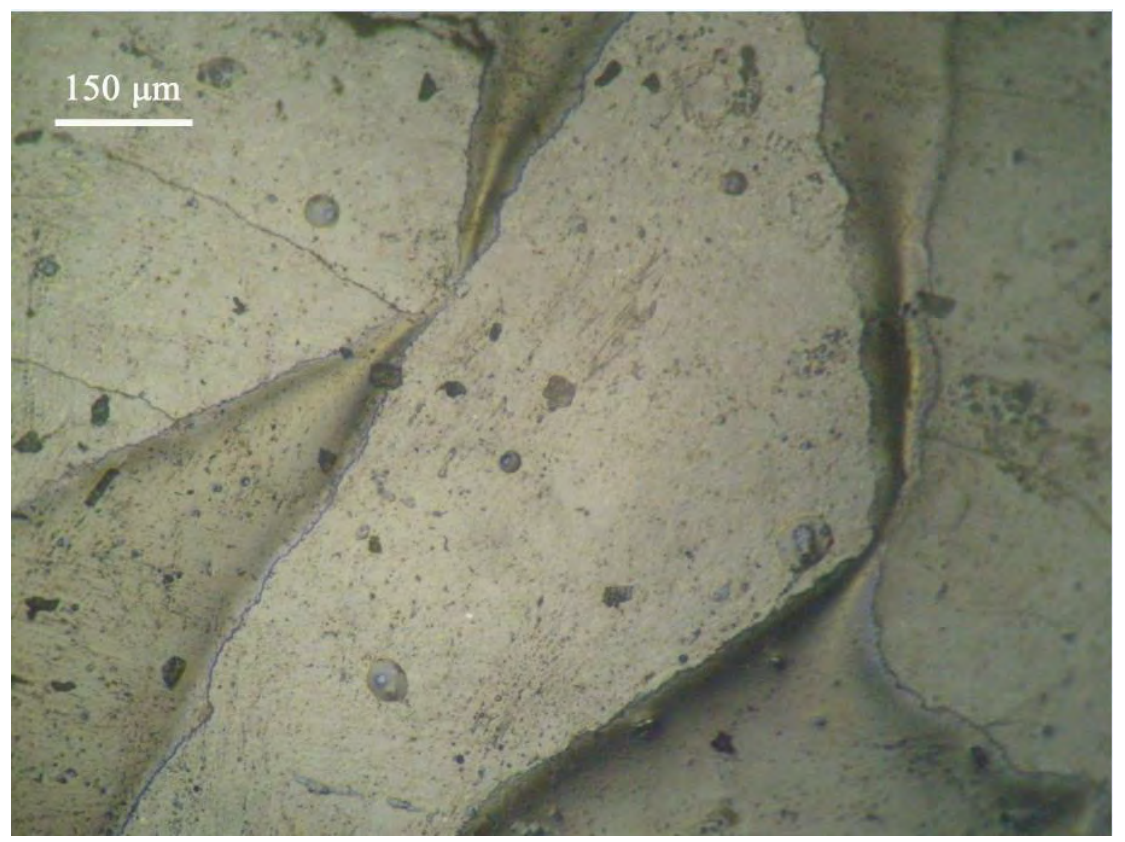

Figure 2 - Polished section, reflected light //Nicols.

Table 1 - Mineralogical composition of the initial sample.

\begin{tabular}{|c|c|c|}
\hline Mineral & Chemical formula & Estimated weight \% \\
\hline Calcite & $\mathrm{CaCO}_{3}$ & 61.2 \\
\hline Francolite & $\mathrm{Ca}_{5}\left(\mathrm{PO}_{4} \cdot \mathrm{CO}_{3}\right)_{3}$ (F.O $)$ & 34.4 \\
\hline Quartz & $\mathrm{SiO}_{2}$ & 4.4 \\
\hline
\end{tabular}

The size analysis of the $-4 \mathrm{~mm}$ crushed sample is presented in Table 2 together with the chemical analysis of each fraction (Bellis, 2013).

Table 2 - Size analysis and chemical analysis of the size fractions.

\begin{tabular}{|l|l|l|l|l|l|l|l|l|}
\hline $\begin{array}{c}\text { Screen } \\
\text { size } \\
\text { fractions } \\
\mathbf{m m}\end{array}$ & $\begin{array}{c}\text { Weight } \\
\mathbf{\%}\end{array}$ & $\begin{array}{c}\mathbf{P}_{2} \mathbf{O}_{5} \\
\mathbf{\%}\end{array}$ & $\begin{array}{c}\mathbf{C a O} \\
\mathbf{\%}\end{array}$ & $\begin{array}{c}\mathbf{F e}_{2} \mathbf{O}_{3} \\
\mathbf{\%}\end{array}$ & $\begin{array}{c}\mathbf{S i O}_{2} \\
\mathbf{\%}\end{array}$ & $\begin{array}{c}\text { LOI } \\
\mathbf{\%}\end{array}$ & $\begin{array}{c}\text { N.D. } \\
\mathbf{\%}\end{array}$ & Total \\
\hline$-4+2$ & 7.24 & 12.12 & 40.44 & 0.27 & 3.03 & 29.55 & 14.59 & 100.00 \\
\hline$-2+1$ & 35.52 & 10.88 & 37.54 & 0.27 & 2.99 & 28.79 & 19.53 & 100.00 \\
\hline$-1+0.5$ & 30.00 & 10.97 & 40.21 & 0.29 & 2.89 & 29.26 & 16.38 & 100.00 \\
\hline$-0.5+0.25$ & 13.10 & 11.02 & 39.44 & 0.30 & 2.98 & 29.53 & 16.73 & 100.00 \\
\hline-0.25 & 14.14 & 13.35 & 46.31 & 0.45 & 3.43 & 29.09 & 7.37 & 100.00 \\
\hline Total & 100.00 & 11.36 & 40.04 & 0.31 & 3.02 & 29.13 & 16.14 & 100.00 \\
\hline
\end{tabular}

Table 2 shows that there is no significant difference of the chemical analysis of the different size fractions with a slight deviation of the very fine fraction. This is a clear index of the luck of liberation between the minerals and confirms what was also observed by the thin section of 
Figure1. The majority constituents are $\mathrm{CaO}$ and $\mathrm{LOI}$ that according to the mineralogical analysis it represents the $\mathrm{CO}_{2}$ of calcite and partially of francolite.

The non detected components are partially due to analytical error but also due to $\mathrm{F}, \mathrm{MgO}, \mathrm{Na}_{2} \mathrm{O}$, and $\mathrm{SO}_{3}$ that according to (Perdikatsis, 1991) are constituents of francolite from Epirus which has the following exact formula.

$\left[(\mathrm{Ca})_{9.86}\right] .\left[(\mathrm{Mg})_{0.08}\right] \cdot\left[(\mathrm{Na})_{0.38}\right] \cdot\left[(\mathrm{PO} 4)_{4.82}\right] \cdot\left[(\mathrm{CO} 3)_{0.95}\right] .\left[(\mathrm{SO} 4)_{0.2}\right] \cdot\left[(\mathrm{F})_{2.34}\right]$

The $\mathrm{F}$ content was measured only in the total sample and is $2.3 \%$, within the specification of a commercial product. According to IGME, the phosphates of western Greece contain small quantities of uranium 15-300 ppm. Radiation measurements made by Professor (Pantinakis, 2013) at the laboratory of Physics of TUC, have shown that it is within acceptable limits and lower than soil samples around TUC.

It is obvious both from the mineralogical and the chemical analysis, as well as from the distribution of the minerals in the various size fractions that the liberation of the minerals is poor and the effort to obtain a $\mathrm{P}_{2} \mathrm{O}_{5}$ rich concentrate is also predetermined to give poor results.

\section{Crushing Tests in a Centrifugal Crusher}

Size reduction tests of the material were performed in a centrifugal crusher using the predetermined size fractions of the material (e.g. 16-22.4 mm, 4-5.6 mm and 1-1.4 mm). The crusher has a rotating disc that accelerates the particles due to its rotation.

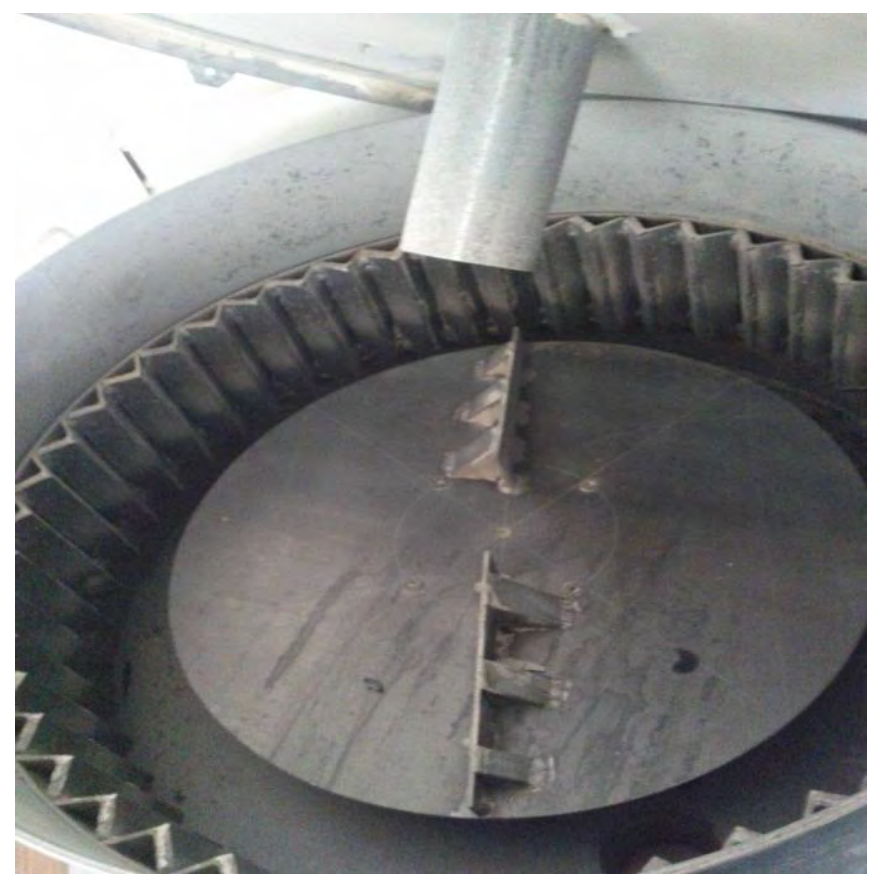

Figure 3 - Inside view of the centrifugal crusher.

The particles leaving the rotating disc are drawn by centrifugal forces towards the periphery and obtain a specific kinetic energy given by Equation 1 (Stamboliadis, 2013).

\section{Equation 1 - Specific Energy Formula}

$e=(\pi \cdot D \cdot N)^{2}$

Table 3 presents the calculated specific energy at the frequencies used for the tests

XLVII, No 3 - 2004 
Table 3 - Frequency - specific energy relationship

\begin{tabular}{|l|l|l|l|l|}
\hline Rotation Frequency (rpm) & 1000 & 1500 & 2000 & 2500 \\
\hline Specific energy $(\mathrm{J} / \mathrm{kg})$ & 685 & 1541 & 2739 & 4279 \\
\hline
\end{tabular}

Separate samples of each size fraction tested are fed to the crusher at the indicated frequencies and the product is screened at the lowest class size of the feed fraction. The mass percentage that passes through the screen is the mass broken below the specific size. The plot of broken mass at the different corresponding specific energies for the feed size-fraction tested is presented in Figure 4.

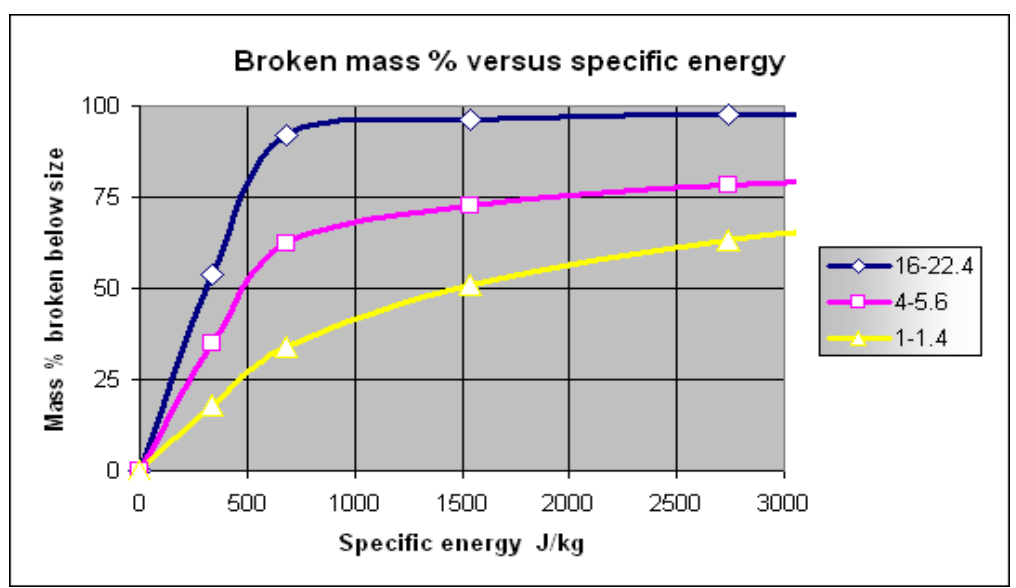

Figure 4 - Broken mass versus specific energy.

According to the model that describes the phenomenon, the breakage specific energy for a size fraction is defined as the one that if exerted on this fraction, half of its mass will be broken below its size class (Stamboliadis et al., 2012). After that, one can find from Figure 4 the corresponding energies $\Delta \mathrm{H}$ for $50 \%$ broken mass for all the size fractions tested.

The corresponding plot of the breakage energy $\Delta \mathrm{H}$ versus size is presented in Figure 5. The relationship is described by the Equation 2.

\section{Equation 2 - Breakage Energy Formula}

$$
\Delta \mathrm{H}=1424 \cdot X^{-0.5564}
$$

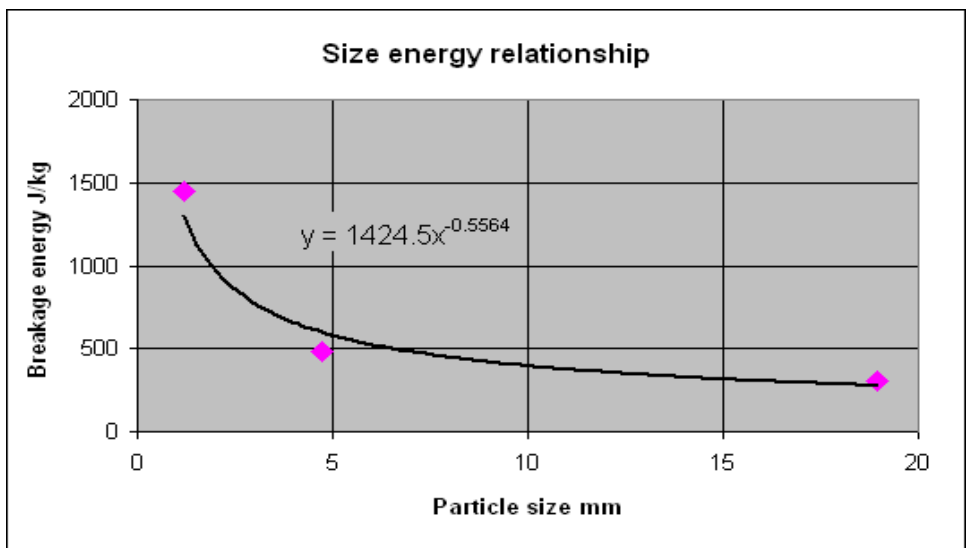

Figure 5 - Breakage energy versus particle size.

XLVII, No 3 - 2005 


\section{Heavy Liquid Tests}

Heavy liquid tests were performed to the size fraction $0.5-4 \mathrm{~mm}$ at liquid densities 2.65 and 2.7 $\mathrm{g} / \mathrm{cm}^{3}$. The cumulative products obtained are presented in Figure 6 for the sinks and in Figure 7 for the floats.

From these two figures one can see that for the same density the sinks have a higher $\mathrm{P}_{2} \mathrm{O}_{5}$ content than the floats and a slightly lower $\mathrm{CaO}$ content. This means that there is an upgrading of the material in the sink products. The evaluation of the best density can be done by comparing the sink products in Figure 6. Obviously the wt \% of the sinks drops at the higher density but the $\mathrm{P}_{2} \mathrm{O}_{5}$ content increases that best result in terms of product grade is obtained at the density of $2.7 \mathrm{~g} / \mathrm{cm}^{3}$. However this grade is only $15.7 \% \mathrm{P}_{2} \mathrm{O}_{5}$ and is not good enough.

The unsatisfactory results of the heavy liquids are obvious due to the insufficient liberation of the ore at the size fraction $0.5-4 \mathrm{~mm}$ tested and in order to overcome this problem it was decided to grind further the ore and try to achieve a better concentration using the froth flotation process.

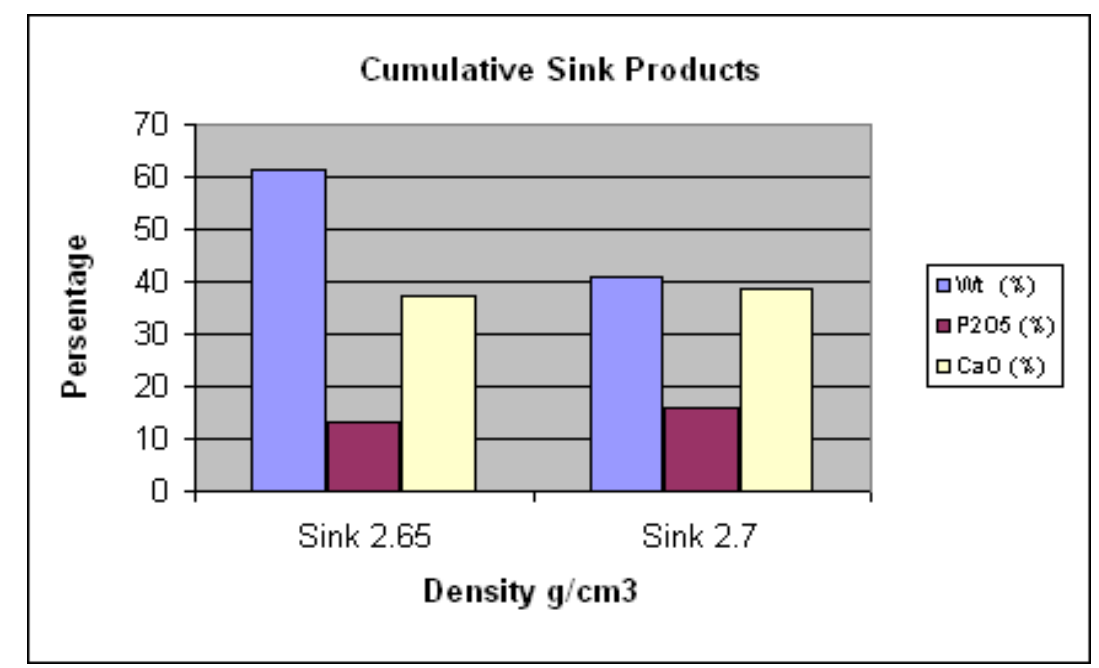

Figure 6 - Cumulative sink products.

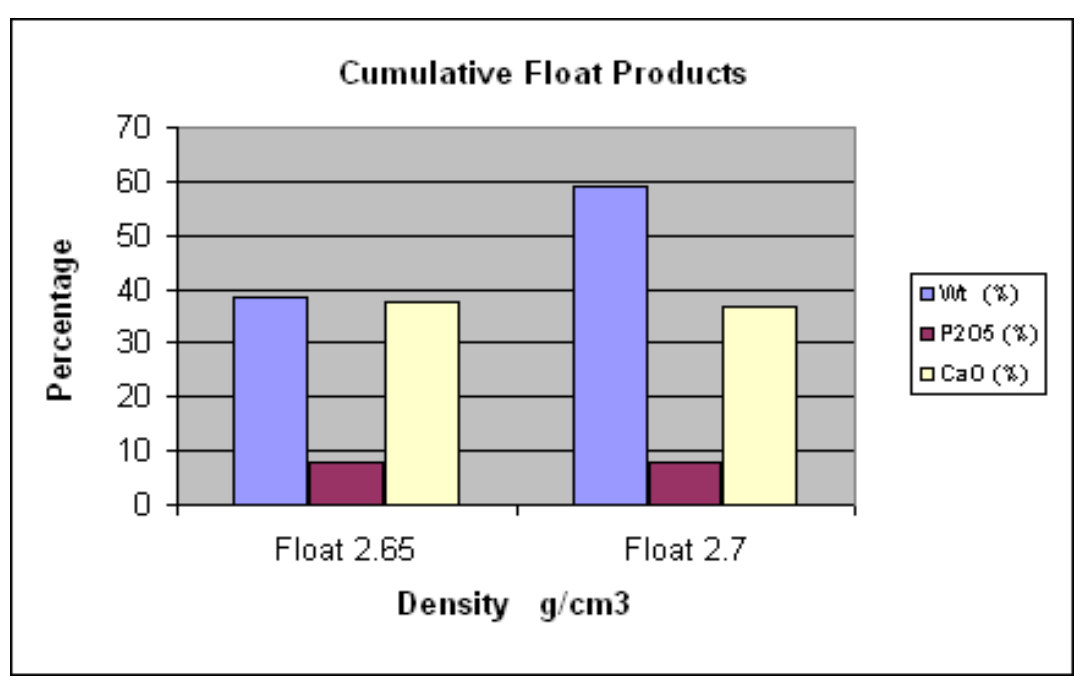

Figure 7 - Cumulative float products.

XLVII, No 3 - 2006 


\section{Flotation Tests}

The size reduction of the ore, necessary for the flotation tests, was performed in the laboratory mill described earlier loaded with $500 \mathrm{~g}$ of feed and $350 \mathrm{ml}$ water at various times. The time chosen to give a d80 size below $200 \mu \mathrm{m}$ is $10 \mathrm{~min}$. The ground product is transferred to the flotation cell adjusted to the right level with water. The reagent is added and the pulp is conditioned for $5 \mathrm{~min}$. After conditioning the air is allowed to enter into the cell. The floating product is collected and the flotation time measured. At the following stage an additional quantity of the reagent is added, conditioned and floated. The process is continued until the floating product collected in minimum. The flotation products were collected and assayed. Two kinds of reagents were used, initially oleic acid and secondly sodium dialkyl phosphate salts of different alkyl lengths, namely propyl, butyl, exyl and octyl.

The results obtained for oleic acid are presented in Figure 8, where one can read the weight of the material remaining in the bottom of the flotation cell as a function of the reagent addition.

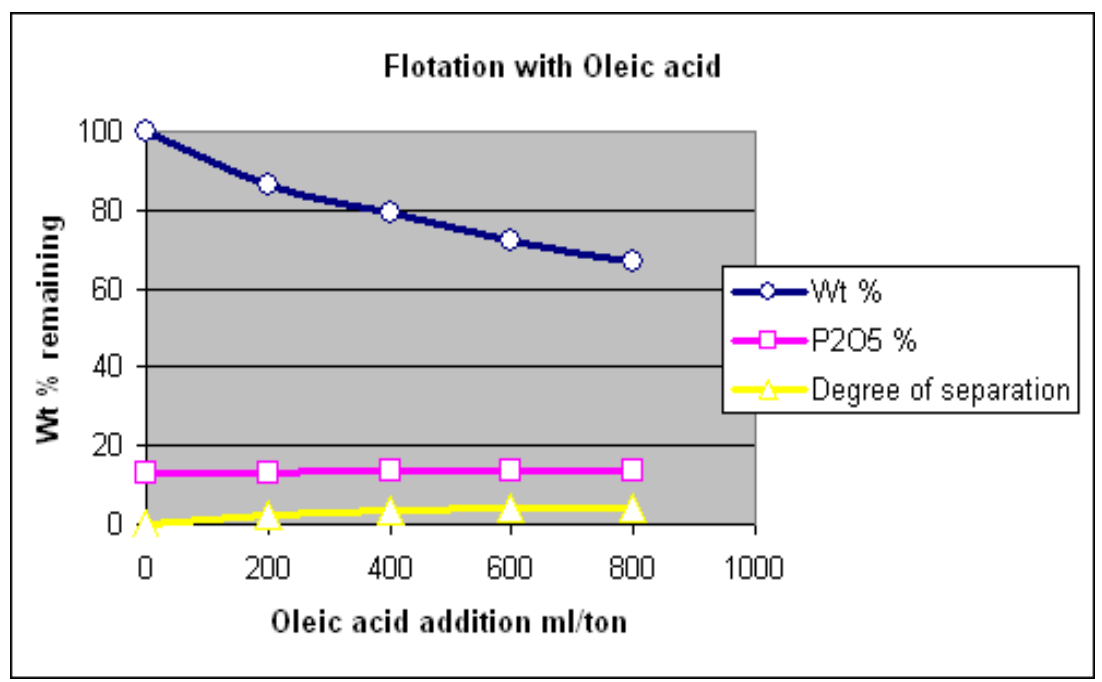

Figure 8 - Flotation with oleic acid.

In the same figure the $\mathrm{P}_{2} \mathrm{O}_{5} \%$ content of the product and the degree of separation (Stamboliadis, 1984) achieved are also plotted. The weight of the product decreases with the addition of the collector but its $\mathrm{P}_{2} \mathrm{O}_{5} \%$ content increases slightly. The degree of separation also increases but still it is not satisfactory. Obviously the floating product contains more $\mathrm{CaO}$ as the collector acts preferably on calcite. The selectivity is not good not only due to bad liberation but also in the fact that both francolite and calcite contain $\mathrm{Ca}$ that reacts with the reagent.

In an effort to investigate a different concentration procedure, a series of sodium dialkylphosphate salts were prepared that have the general formula $\mathrm{NaR}_{2} \mathrm{PO}_{4}$ where $\mathrm{R}$ is selected to be propyl, butyl, exyl and octyl. It was expected that these reagents could be more selective and that the length of their organic chain could play a role in the process.

The results are plotted in Figure 9 that shows the $\mathrm{wt} \%$ of the product remaining in the flotation cell as a function of reagent addition. One can see that the remaining mass decreases as the number of carbons in the alkyl group increases from 3 to 8, or the same from propyl to octyl, How-ever the $\mathrm{P}_{2} \mathrm{O}_{5} \%$ content of the floating and the remaining products is practically the same indicating no selectivity of all these reagents although the differ in the mass that they can drive with the froth.

Although for the flotation tests, the material is ground finer but the results obtained were even worse than those noted by the heavy liquids in a coarser size. Similar unsatisfactory results were obtained by Tsailas et al. (1980) and Anastassakis (1989).

XLVII, No 3 - 2007 


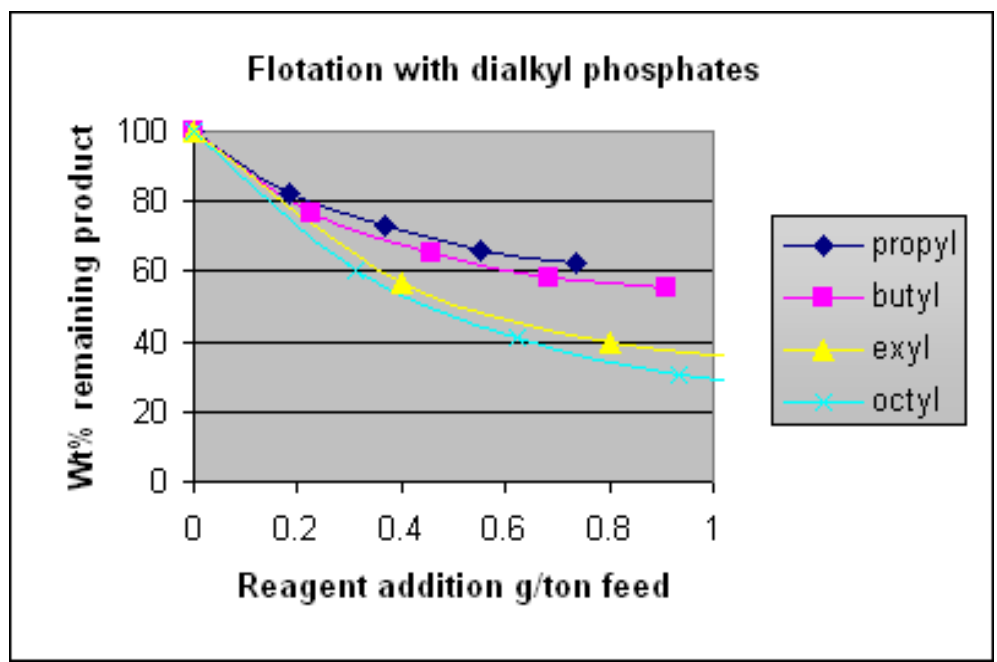

Figure 9 - Flotation with dialkyl-phosphates.

\section{Calcinations and Hydrolysis Tests}

Given the inability of the flotation process to produce a high grade concentrate, mainly due to the insufficient liberation, it was decided to abandon physicochemical separation methods and proceed with metallurgical and chemical methods. The aim was to separate francolite from calcite. The idea comes from the fact, that at high temperature, calcite decomposes to $\mathrm{CaO}$ and $\mathrm{CO}_{2}$ that escapes to the atmosphere. The remaining $\mathrm{CaO}$ is easily hydrated with water to give $\mathrm{Ca}(\mathrm{OH})_{2}$ that is diffused into the water in small molecular agglomerates that form a milky suspension. These fine $\mathrm{Ca}(\mathrm{OH})_{2}$ agglomerates could be easily separated by size from the remaining francolite grains that hopefully would retain their initial size.

For this purpose, a quantity of the material, ground to $-0.5 \mathrm{~mm}$, was calcined at $950{ }^{\circ} \mathrm{C}$ that caused $29 \%$ loss of weight due to the evolution of $\mathrm{CO}_{2}$. After calcination, $100 \mathrm{~g}$ of the calcined product are added into one liter of water with initial temperature $16{ }^{\circ} \mathrm{C}$. The pulp temperature eventually increases to $22^{\circ} \mathrm{C}$ and the $\mathrm{pH}$ of the suspension to 12.5 . Both of these differences indicate that an exothermic reaction takes place that gives $\left(\mathrm{OH}^{-}\right)$hydroxyl anions into the solution. The suspension is agitated very slightly and after one hour it is screened at $63 \mu \mathrm{m}$. The screen undersize and oversize are filtered, dried, weighted and assayed. The results are presented in Table 4.

Table 4 - Results after the hydration of the calcined sample.

\begin{tabular}{|c|c|c|c|c|c|}
\hline Size & $\begin{array}{c}\mathbf{W t} \\
\mathbf{\%}\end{array}$ & $\begin{array}{c}\mathbf{P}_{2} \mathbf{O}_{5} \\
\mathbf{\%}\end{array}$ & $\begin{array}{c}\mathbf{C a O} \\
\mathbf{\%}\end{array}$ & $\begin{array}{c}\mathbf{S i O}_{2} \\
\mathbf{\%}\end{array}$ & $\begin{array}{c}\text { LOI } \\
\mathbf{\%}\end{array}$ \\
\hline$+63 \mu \mathrm{m}$ & 76,1 & 13.43 & 43.57 & 3.05 & 11.02 \\
\hline$-63 \mu \mathrm{m}$ & 23,9 & 9.02 & 49.13 & 2.35 & 24.09 \\
\hline
\end{tabular}

Table 4 shows that the $\mathrm{P}_{2} \mathrm{O}_{5}$ and $\mathrm{SiO}_{2}$ contents are increased in the coarse fraction, while the $\mathrm{CaO}$ and LOI are increased in the fine fraction. It must be reminded that after calcination and hydration, there is no more $\mathrm{CaCO}_{3}$ and the LOI is due to the decomposition of the $\mathrm{Ca}(\mathrm{OH})_{2}$ that evolves $\mathrm{H}_{2} \mathrm{O}$. In any case there is a difference in the two products but still the result is not satisfactory.

\section{Discussion and Conclusions}

The sample of phosphate ore $\left(11.4 \% \mathrm{P}_{2} \mathrm{O}_{5}\right)$ tested originates from the area of Epirus, Western Greece. Its main mineralogical constituents are francolite, the $\mathrm{P}_{2} \mathrm{O}_{5}$ bearing mineral, and calcite, the gangue one that is the most abundant and is responsible for the low quality of the ore. The two

$\underline{\text { XLVII, No } 3-2008}$ 
minerals are very finely disseminated in the orebody and practically it is difficult, if not impossible, to liberate. The unique difference in the quality that appears is in the parallel zones, a few $\mathrm{mm}$ thick, of different calcite content that characterize the stromatography of the orebody obtained during different sedimentation events. This is the reason for which at relative coarse size $0.5-4 \mathrm{~mm}$ we were able to obtain the best possible product with $15.7 \% \mathrm{P}_{2} \mathrm{O}_{5}$ compared to flotation, where although the ore is finely ground the product assays $13.0 \% \mathrm{P}_{2} \mathrm{O}_{5}$ in the case of using oleic acid as collector.

The calcination and successive hydration tests have shown a tendency of separation that still is not efficient and needs further study. However the high cost of calcination, especially for such a low quality ore seems to be an opposing factor towards this direction.

It is recommended that further research in the processing of the ore should be combined with a parallel geological research to define places of higher ore grade and probably weathered material that perhaps could be easier to upgrade.

\section{References}

Anastassakis G. 1989. Contribution to the beneficiation of the unaltered phosphate rock of Epirous area (Greece), PhD Thesis, National Technical University, Greece, (in Greek).

Bellis G. 2013. A study for the upgrading of phosphate rock from Western Greece, Undergraduate Thesis, Technical University of Crete, Greece. (in Greek).

Pantinakis A. 2013. Professor of Physics, Technical University of Crete, Greece, Personal communication.

Perdikatsis B. 1991. X-Ray power diffraction study of Francolite by the Rietveld method, Mat. Science Forum, Vols. 79-82, pp 809-814.

Stamboliadis D. 2013. Design of a centrifugal crusher for minerals, based on the design of structures, Undergraduate Thesis, Technological Education Institute of Piraeus (TEI Piraeus) (in Greek).

Stamboliadis E. 1984. Measure of Separation, IMM, Transactions Section C, Vol 93, C16-C19.

Stamboliadis E., Stamboliadis D., Kiskira K. and Emejulu E., 2012. Crushing of mineral particles by control of their kinetic energy, Material Science and Applied Chemistry, $53^{\text {rd }}$ International Scientific Conference, Riga, Technical University.

Tsailas D., Grossou-Valta M. and Kalatzis G. 1980. Study on the possibilities of beneficiating Epirus unaltered phosphate rocks, IGME Publications, 016823. (in Greek). 